\title{
Estimation of forest leaf area index using satellite multispectral and synthetic aperture radar data in Iran
}

\author{
Sasan Vafaei ${ }^{(1)}$, \\ Omid Fathizadeh ${ }^{(2)}$, \\ Nicola Puletti ${ }^{(3)}$, \\ Hadi Fadaei ${ }^{(4)}$, \\ Sabri Baqer Rasooli ${ }^{(5)}$, \\ Gaia Vaglio Laurin ${ }^{(3-6)}$
}

\begin{abstract}
Different satellite datasets, including multispectral Sentinel 2 and synthetic aperture radar Sentinel 1 and ALOS2, were tested to estimate the Leaf Area Index (LAI) in the Zagros forests, Ilam province, in Iran. Field data were collected in 61 sample plots by hemispherical photographs, to train and validate the LAl estimation models. Different satellite data combinations were used as input in regression models built with the following algorithms: Multiple Linear Regression, Random Forests, and Partial Least Square Regression. The results indicate that Leaf Area Index can be best estimated using integrated ALOS2 and Sentinel 2 data; these inputs generated the model with higher accuracy $\left(R^{2}=0.84\right)$. The combination of a single band and a vegetation index from Sentinel 2 also led to successful results $\left(R^{2}=0.81\right)$. Lower accuracy was obtained when using only ALOS $2\left(R^{2}=0.72\right)$, but this dataset is helpful where cloud coverage affects optical data. Sentinel 1 data was not useful for LAl prediction. The optimal model was based on the traditional Multiple Linear Regression algorithm, using a preliminary input selection step to exclude multicollinearity effects. To avoid this step, the use of Partial Least Square Regression may be an alternative, as this algorithm was able to produce estimates similar to those obtained with the best model.
\end{abstract}

\section{Keywords: Leaf Area Index, Sentinel 2, ALOS 2, Forest Monitoring}

health, being linked to leaf and canopy chlorophyll contents, dry and fresh biomass, and growth stages (Vose \& Allen 1988). LAI is frequently used by foresters and ecologists to simulate ecological processes, as well as by agronomists and crop modelers to model crops dynamics and productivity, and is one of the most important indices to monitor vegetation status and estimate productivity (Leuschner et al. 2006). Although direct measurements of canopy LAl give relatively precise values, data collection is time-consuming and labor-intensive, and only feasible in smallscale plots. Remote sensing-based LAI estimates now complement the ground measurements, thanks to the capability of re-
(1) Faculty of Agriculture and Natural Resources, Lorestan University, Khorramabad, Lorestan (Iran); (2) Department of Forestry, Ahar Faculty of Agriculture and Natural Resources, University of Tabriz (Iran); (3) Research Centre for Forestry and Woodland, Council for Agricultural Research and Economics, Arezzo (Italy); (4) Department of Geography, Amin Police University, Tehran (Iran); (5) Department of Forestry, Faculty of Natural Resources, University of Guilan, Someh Sara (Iraq); (6) Department for Innovation in Biological, Agrofood and Forest systems, Tuscia University, Viterbo (Italy)

@ Gaia Vaglio Laurin (gaia.vl@unitus.it)

Received: Aug 24, 2020 - Accepted: Apr 08, 2021

Citation: Vafaei S, Fathizadeh O, Puletti N, Fadaei H, Baqer Rasooli S, Vaglio Laurin G (2021). Estimation of forest leaf area index using satellite multispectral and synthetic aperture radar data in Iran. iForest 14: 278-284. - doi: 10.3832/ifor3633-014 [online 2021-05-29]

Communicated by: Agostino Ferrara mote data to cover large extents repeatedly in time, and generate LAl estimated values at local and global scales.

Several approaches are available to estimate LAI using remote sensing methods. The gap fraction method (Norman \& Campbell 2000) is based on the use of below canopy hemispherical images and is often adopted at local or stand scale to collect LAI information, due to its fast and non-destructive nature. The hemispherical photographs capture the patterns of light obstruction/penetration in the canopy, from which the canopy architecture and foliage area can be quantified (Fournier et al. 1996); LAI and other canopy properties are estimated through the measurement of radiation transmitted through the canopy and the application of radiative transfer models (Ross 1981). In recent years, digital hemispherical photography has received increasing attention as an inexpensive tool for near-surface remote sensing of forest canopy structure, with research carried out in multiple environments (Brown et al. 2020, Zou et al. 2020, Díaz et al. 2021).

Other studies were based on the use of satellite multispectral data for LAI prediction, exploiting the direct relationship that links canopy reflectance values with foliage density (Korhonen et al. 2017, Verrelst et al. 2015). However, the availability of optical data is often hampered by the presence of cloud coverage. Indeed, a saturation of reflectance response is observable at high LAI values, and consequently no information can be gathered about the understory 
vegetation or the woody stand structure (Torbick et al. 2016).

To cope with the limitations occurring in optical data, microwave Synthetic Aperture Radar (SAR) data were adopted in agricultural and forestry research for LAI estimation. SAR data are insensitive to cloud and day/night conditions. Furthermore, the intensity of the backscattered SAR signal is related to the target volume and its water content, with the penetration of SAR depending on the wavelength used. Usually, at L- and P-long wavelengths the signal penetration into the vertical profile is high, and SAR can sense the different vegetation strata. At shorter wavelength, such as C-band, the information mainly comes from the upper canopy layer (Solberg \& Weydahl 2007).

Multiple examples are reported in the literature about the use of SAR data, mainly C-band, to estimate $\mathrm{LAI}$ in different crops (Jiao et al. 2011, Inoue et al. 2014, Mandal et al. 2019), as well as in grasslands (Lu \& He 2019). Yet, fewer studies were carried out in forest environments. In the Amazon varzea forest, Pereira et al. (2018) used different SAR sensors including ALOS PALSAR at L-band to retrieve both above ground biomass and LAI, showing that ALOS PALSAR provided the best estimates of both variables with respect to other SAR datasets. Stankevich et al. (2017) developed a method for LAl estimation in temperate deciduous and mixed forests using Sentinel 1 at C-band. Chen et al. (2017) compared the performances of various optical sensors with those of ALOS PALSAR for LAI estimation, showing that the addition of SAR brought new information in the opticalbased LAI regression model, and suggested the combined use of optical AVNIR-2 and microwave PALSAR, that are on the same ALOS platform. Manninen et al. (2005) developed a method for assessing LAI in boreal forests using ENVISAT C-band SAR data polarization ratio $(\mathrm{VV} / \mathrm{HH})$; using the same sensor, Gao et al. (2010) evi- denced the sensitivity of SAR backscattering at different polarizations to LAI in poplar and desert date forest plantations in China.

The objective of this study was to compare the single and combined use of multispectral and SAR data for LAl estimation in a Mediterranean forest site. Specifically, the use of SAR was tested to offer an alternative to multispectral data when cloud coverage affects the quality of optical imagery. Different algorithms were tested, including Multilinear Regression, Random Forests, and Partial Least Squared Regression, to improve the accuracy of results and to facilitate the processing task. The results were rigorously validated and compared to each other to offer a perspective on LAl estimation in forest analysis.

\section{Methods}

\section{Study area}

The study was carried out in the Southern Zagros protected forest, in the Dalab region of the western Iranian state of Ilam (Fig. 1). This is a sub-Mediterranean region, characterized by marked seasonality in rainfall distribution. The altitude ranges from approximately 1300 to $2200 \mathrm{~m}$ a.s.l., with average slopes equal to $17^{\circ}$. The main woody species in this area is the Brant's oak (Quercus brantii), usually found in pure stands and covering about 3.5 million hectares in Zagros. Other species that are often present include: Pistacia atlantica, Acer spp., Crataegus azarolus, Cerasus microcarpa, Daphne mucronate, Amygdalus orientalis, Lonicera nummularifolia. The density of stands varies across the study area, in the range of 30-100 trees per hectare; the average forest coverage is about $45 \%$. Seasonally, the ground is covered by grasses (Sagheb-Talebi et al. 2014).

\section{Satellite data}

Three different satellite datasets were used: (i) multispectral Sentinel 2 (L1C1)
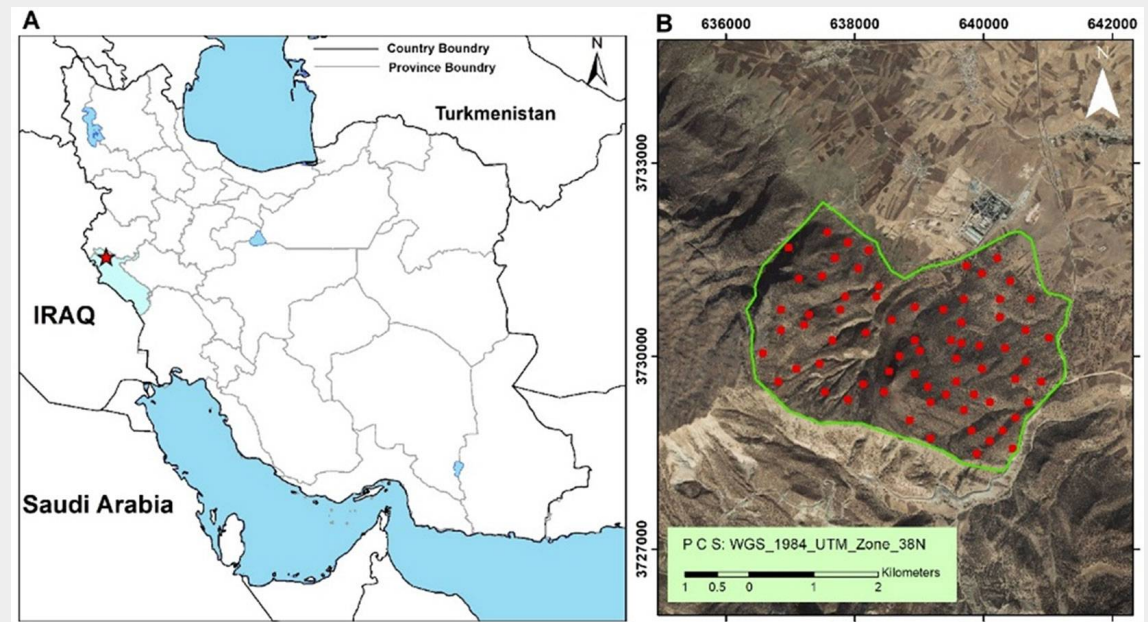

Fig. 1 - (A) Geographic location of the study area (red star); (B) location of the field plots (red dots). dated July 23, 2016; (ii) SAR Sentinel 1 (L1C HRD) dated June 8, 2016; and (iii) ALOS2 (level 1.1 SLC), dated June 23, 2016. Satellite data processing was carried out in SNAP, the free processing facilities offered by the European Space Agency (ESA - http://step. esa.int/main/toolboxes/snap/).

The Sentinel 2 (S2) instrument samples 13 spectral bands in the visible-near infrared (VIS-NIR) to the shortwave infrared (SWIR) range, with four bands at $10 \mathrm{~m}$, six bands at $20 \mathrm{~m}$ and three bands at $60 \mathrm{~m}$ spatial resolution; it also incorporates three bands in the red-edge region, centered at 705, 740 and $783 \mathrm{~nm}$. The S2 image was atmospherically corrected using the ESA Sen2Cor algorithm. For the present study, ten original bands at $10-20 \mathrm{~m}$ spatial resolution and 22 vegetation indices listed in Tab. S1 (Supplementary material) were used as inputs in models to predict LAI.

Sentinel 1 (S1) is an SAR constellation equipped with C-band sensors and has a 6 day repeat cycle. For this research, the Sentinel-1A Interferometric Wide swath mode (IW), Level-1 Ground Range Detected (GRD) scene with dual-polarization (VV and $\mathrm{VH})$ was used. The scene has a pixel spacing equal to $10 \mathrm{~m}$ and an incidence angle of approximately $39-40^{\circ}$; it was calibrated, filtered with the refined Lee filter to reduce speckle noise, and terrain corrected using the SRTM-1 Sec DEM (Shuttle Radar Topography Mission-3 Digital Elevation Model), to produce a regular grid of $20 \mathrm{~m}$ spatial resolution size. Finally, it was co-registered with the Sentinel-2 scene. The two VV and $\mathrm{VH}$ polarizations were used as input in models to predict LAI.

The Advanced Land Observing Satellite-2 (ALOS-2) carries on the PALSAR2 L-band SAR sensor. Level 1.1 data single look complex (SLC) fine beam scene, in $\mathrm{HH}$ and HV polarizations with an incidence angle of $34.3^{\circ}$, and $12.5 \mathrm{~m}$ pixel spacing were acquired, multilooked, filtered for speckle noise using the refined Lee filter, and terrain corrected using the SRTM-1 Sec DEM. The final spatial resolution was set to $20 \mathrm{~m}$ and the scene was co-registered with the Sentinel-2 image.

\section{Field plots}

Sixty-one plots of $40 \times 40 \mathrm{~m}$ were set up in the study area, recording their center with a GPS device eTrex ${ }^{\oplus} 20$ (Garmin, Schaffhausen, Switzerland). In each plot, a $4 \times 3$ grid defined 12 points, each being 8-10 $\mathrm{m}$ apart from the neighboring one: the points corresponded to locations where digital hemispherical photographs (DHP) images were collected at sunrise under uniform sky conditions. The DHP were collected using a digital camera $\left(\mathrm{EOS}^{\oplus} 6 \mathrm{D}\right.$, Canon, Tokyo, Japan) fitted with a fisheye adapter lens (EF Lens 24-105mmF4 L IS USM, Canon, Tokyo, Japan). LAI was calculated from the DHP images using the Gap Light Analyzer software, based on the Beer-Lambert Law and the Miller equation for foliage density (Miller 1967). 
Data analysis and modeling

The pixels included in the field plot areas were extracted from the different optical (S2) and microwave (S1 and ALOS2) satellite datasets. Pixels were averaged at plot level, obtaining the reflectance and the backscattering values of each plot. A preliminary correlation analysis showed high correlation of field LAI values with different satellite data.

The most relevant predictors $(p<0.05)$ from $S_{1}, S_{2}$, and ALOS2 datasets were identified through stepwise regression (alpha to enter and remove $=0.15-$ Tab. 1 ). The stepwise procedure allows the number of inputs in models to be reduced, thereby avoiding multicollinearity effects, or inflating the regression models.

Three different algorithms were used to build the LAI regression models. The first, Multiple Linear Regression (MLR), is a statistical technique that exploits several explanatory variables to predict the outcome of a response variable, widely used in forest research for its simplicity of application; basically, it is an extension of the ordinary least-squares (OLS) regression that involves more than one explanatory variable (Freedman 2009).

The second algorithm, Random Forests (RF), is a supervised "ensemble learning" method able to cope with complex datasets (Breiman 2001). RF generates many regression trees (models) and aggregates their results, exploiting the bootstrap aggregation method, reducing the output variance and of the overfitting problem. The $n$-trees and the m-try are the only two parameters that must be chosen to train the RF model, making its application smoother when compared to more complex machine learning algorithms. During the training phase, each tree is built by a growing process implementing different cascaded nodes, representing the ramification of a tree. Data kept separate from the training subsets are called "Out-Of-Bag" (OOB) samples and are used to validate the model and define the associated OOB error, also called the "Out-Of-Bag estimate". The latter is the mean prediction error on each training sample, computed us-

Tab. 1 - Input’s data in stepwise regression. (§): see Tab. S1 in Supplementary material.

\begin{tabular}{llc}
\hline Dataset & Variables & $\begin{array}{c}\text { Number } \\
\text { of inputs }\end{array}$ \\
\hline Sentinel 2 & $\begin{array}{l}\text { Bands: B2, B3, B4, B5, B6, B7, B8, B8a, B11, and B12; } \\
\text { 17 Vegetation Indices }\end{array}$ & 32 \\
Sentinel 1 & $\mathrm{VH}, \mathrm{VV}, \mathrm{VV} / \mathrm{VH}, \mathrm{VH}+\mathrm{VV}, \mathrm{VH}-\mathrm{VV}$ & 5 \\
\hline ALOS 2 & $\mathrm{HH}, \mathrm{HV}, \mathrm{HH} / \mathrm{HV}, \mathrm{HH}+\mathrm{HV}, \mathrm{HH}-\mathrm{HV}$ & 5 \\
\hline
\end{tabular}

ing only the trees that did not include the same samples in their bootstrap dataset (Breiman 2001). Random Forests is commonly applied in remote sensing and forest ecology (Vittucci et al. 2019).

Finally, Partial Least Squared Regression (PLSR), closely related to principal component regression, was selected as an additional algorithm given its ability to deal with multicollinearity issues and the "curse of dimensionality". PLSR uses the information from the response variable in addition to the predictors for feature transformation (Geladi \& Kowalski 1986); this algorithm is commonly used in ecological and forestry applications exploiting large, complex datasets (Vaglio Laurin et al. 2013).

LAI estimation models were first built using the inputs selected by stepwise regression, setting three Multiple Linear Regression models: MLR M1 using multispectral data, MLR M2 using SAR data, and MLR M3 using integrated optical-SAR datasets. MLR $\mathrm{M}_{3}$ input data - characterized by different optical and SAR physical properties - were then used as input in the Random Forests algorithm (named RF M4). Finally, to avoid running a preliminary stepwise regression, all the available predictors were used as input in Partial Least Squared Regression algorithm (models named PLSR M5, PLSR M6, PLSR M7). PLSR was also run using the stepwise selected optical and SAR inputs (model PLSR M8), for comparison purposes with MLR M3 and RF M4. All the models were validated with 10-fold cross validation (Tab. 2). MLR and RF models were evaluated by the coefficient of determination $\left(R^{2}\right)$ and the Root Mean Squared Error (RMSE) statistical metrics; PLSR models were evaluated using the $R^{2}$ and the
PRESS statistics (minimum predicted residual sum of squares).

Using the most accurate model, a map of estimated LAI was generated for the entire study area.

\section{Results}

The summary statistics of the LAl measured in sample plots shows that LAI values for the site are normally distributed, and range between 0.59-2.66 (Tab. 3). The results of Pearson's correlation analysis between LAl and the various satellite predictors are presented in Tab. 4; the relationships were consistently linear.

In general, the correlations were high with Sentinel 2 and ALOS2 predictors with multiple data, obtaining values in the range o.8-0.9. A much lower correlation was noted for Sentinel 1 predictors.

The stepwise regression based on Sentinel 2 bands and vegetation indices selected band 4 and ARVI, and obtained an adjusted $R^{2}$ equal to 79.93 , with a variable inflation rate (VIF), equal to 3.7. For Sentinel 1 the stepwise regression selected $\mathrm{VH}$ input only, with a very low adjusted $\mathrm{R}^{2}$ equal to 4.45. For ALOS2, the selected input was $\mathrm{HV}$, with an adjusted $\mathrm{R}^{2}$ equal to

Tab. 3 - Descriptive statistics of LAI measured in the study plots $(N=61)$.

\begin{tabular}{lc}
\hline Statistics & Value \\
\hline Minimum & 0.59 \\
\hline Maximum & 2.66 \\
\hline Mean & 1.66 \\
\hline Std. Deviation & 0.52 \\
\hline
\end{tabular}

Tab. 2 - Algorithms and input data used in the different regression tests.

\begin{tabular}{llll}
\hline Model & Algorithm & Variables & $\begin{array}{c}\text { Number } \\
\text { of inputs }\end{array}$ \\
\hline MLR M1 - multispectral & Multiple Linear Regression & B4, ARVI & 2 \\
\hline MLR M2 - SAR & Multiple Linear Regression & ALOS2 HV & 1 \\
\hline MLR M3 - multispectral + SAR & Multiple Linear Regression & B4 + ARVI + ALOS2 HV & 3 \\
\hline RF M4 - multispectral + SAR & Random Forests & B4 + ARVI + ALOS2 HV & 3 \\
\hline PLSR M5 - multispectral & Partial Least Squared Regression & 10 S2 bands + 22 vegetation indices (as in Tab. 1) & 32 \\
\hline PLSR M6 - SAR & Partial Least Squared Regression & 5 S1 + 5 ALOS2 inputs (as in Tab. 1) & 10 \\
\hline PLSR M7 - multispectral + SAR & Partial Least Squared Regression & 10 S2 bands + 22 vegetation indices + 5 ALOS 2 inputs & 37 \\
\hline $\begin{array}{l}\text { PLSR M8 - selected multispectral } \\
\text { + SAR }\end{array}$ & Partial Least Squared Regression & B4 + ARVI + ALOS2 HV & 3 \\
\hline
\end{tabular}


Tab. 4 - Pearson's correlation coefficients between LAI and satellite predictors. $(*): p<0.05 ;(* *): p<0.01$.

\begin{tabular}{llllllc}
\hline Dataset & Bands /indices & $r$ & Bands / indices & $r$ & Bands / indices & $r$ \\
\hline Sentinel 2 & B2 & $-0.765^{*}$ & PVI & $0.767^{*}$ & WDVI & $0.750^{*}$ \\
& B3 & $-0.790^{*}$ & RVI & $0.590^{*}$ & Tsavi & $0.834^{*}$ \\
& B4 & $-0.888^{*}$ & NDVI & $0.882^{*}$ & ARVI & $0.828^{*}$ \\
& B5 & $-0.797^{* *}$ & DVI & $0.767^{*}$ & NDI45 & $-0.404^{* *}$ \\
& B6 & $-0.682^{* *}$ & GNDVI & $0.759^{*}$ & REIP & -0.169 \\
& B7 & $-0.603^{* *}$ & IPVI & $0.882^{*}$ & IRECI & $0.799^{* *}$ \\
& B8a & $-0.561^{*}$ & Msavi & $0.826^{*}$ & NDI705 & $0.773^{* *}$ \\
& B8 & $-0.597^{*}$ & NDII & $0.665^{*}$ & S2REP & -0.169 \\
Sentinel 1 & B11 & $-0.426^{*}$ & SAVI & $0.846^{*}$ & MCARI & $0.328^{*}$ \\
ALOS 2 & B12 & $-0.417^{* *}$ & SIPI & $0.602^{*}$ & MTCI & -0.243 \\
& - & - & TNDVI & $0.886^{*}$ & PSSRA & $0.588^{*}$ \\
& VH & $0.246^{*}$ & VH+VV & $0.234^{*}$ & VV/VH & -0.045 \\
\hline
\end{tabular}

Tab. 5 - Model results for Leaf Area Index regression, validated with 10-fold cross validation.

\begin{tabular}{|c|c|c|c|c|}
\hline Algorithm & Model & $\mathbf{R}^{2}$ & $\begin{array}{c}\text { RMSE } \\
\left({ }^{\ddagger} \text { PRESS) }\right.\end{array}$ & Inputs \\
\hline \multirow{3}{*}{$\begin{array}{l}\text { Multiple } \\
\text { Linear } \\
\text { Regression }\end{array}$} & MLR M1 - multispectral & 0.81 & 14.25 & B4, ARVI \\
\hline & MLR M2 - SAR & 0.72 & 19.13 & ALOS2 HV \\
\hline & MLR M3 - multispectral + SAR & 0.84 & 13.52 & $B 4+A R V I+A L O S 2 H V$ \\
\hline $\begin{array}{l}\text { Random } \\
\text { Forests }\end{array}$ & RF M4 - multispectral + SAR & 0.83 & 13.56 & $B 4+A R V I+A L O S 2 H V$ \\
\hline \multirow{4}{*}{$\begin{array}{l}\text { Partial Least } \\
\text { Squared } \\
\text { Regression }\end{array}$} & PLSR M5 - multispectral & 0.77 & $\ddagger 3.72$ & 10 S2 bands +22 vegetation indices (as in Tab. 1 ) \\
\hline & PLSR M6 - SAR & 0.61 & ${ }^{\ddagger} 6.35$ & $5 \mathrm{~S} 1+5$ ALOS2 inputs (as in Tab. 1) \\
\hline & PLSR M7 - multispectral + SAR & 0.8 & ‡3.27 & $\begin{array}{l}10 \text { S2 bands }+22 \text { vegetation indices + } 5 \text { ALOS } 2 \text { inputs } \\
\text { (as in Tab. 1) }\end{array}$ \\
\hline & PLSR M8 - selected multispectral + SAR & 0.81 & $\neq 3.04$ & $B 4+A R V I+A L O S 2 H V$ \\
\hline
\end{tabular}

62.55 . models, validated with 10-fold cross valida- and ALOS2 HV polarization $\left(R^{2}=0.84\right.$; residuals (equal to 2.35 and -2.15$)$ and one tion, are illustrated in Tab. 5, which shows RMSE =13.52). Fig. 2 shows the scatterplot unusual observation (equal to -1.31 ) these that the best accuracy is obtained using of predicted vs. observed LAl values for two observations were kept in the model

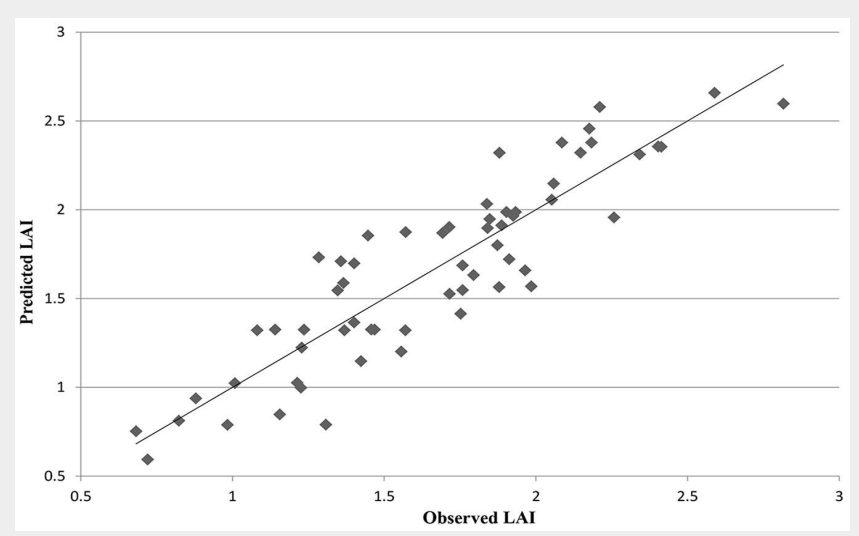

Fig. 2 - Predicted vs. observed LAI values, generated with the MLR M3 model based on Sentinel 2 (band 4 and ARVI vegetation index) and ALOS2 (HV polarization) inputs, with $\mathrm{R}^{2}$ equal to 0.84 and according to the following equation: $\mathrm{LAI}=3.133-6.00$ $\mathrm{B} 4+0.769 \mathrm{ARVI}+0.0820 \mathrm{HV}$.

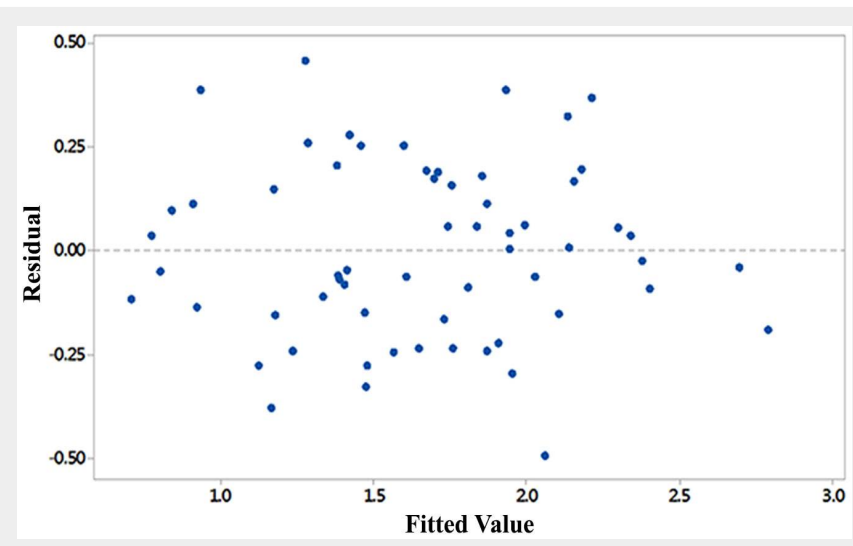

Fig. 3 - Residuals vs. fitted LAI values, generated with the MLR 3 model on Sentinel 2 and ALOS2 inputs, with $R^{2}$ equal to 0.84 and according to the following equation: $\mathrm{LAI}=3.133-6.00 \mathrm{~B} 4+$ $0.769 \mathrm{ARVI}+0.0820 \mathrm{HV}$. 
as they did not impact its accuracy, and because no evidence of errors was found in the related field or remote sensing data. Fig. 3 shows the scatterplot of residuals vs. fitted values for MLR3. Using the equation listed in the caption of Fig. 2, the LAI map for the study areas was generated, as shown in Fig. 4.

\section{Discussion}

This research illustrates how to accurately estimate $\mathrm{LAl}$ in the Zagros protected forest based on satellite and field data.

Using Sentinel 2 inputs, the accuracy $\left(R^{2}\right)$ of LAl estimates resulted equal to 0.77 (with PLSR, based on 32 inputs) and 0.81 (with MLR, based on two stepwise selected inputs), respectively. Both these results are higher with respect to values obtained by Stenberg et al. (2004), who used Landsat ETM data in conifer forests $\left(R^{2}\right.$ equal to 0.63); by Zhang et al. (2011), who used IRS P6 LISS 3 imagery in a bamboo forest ( $R^{2}$ equal to 0.68 ); and by Korhonen et al. (2017), who used Sentinel 2 in boreal forests ( $R^{2}$ equal to 0.73). On the other hand, the results of the present study are slightly less accurate than those obtained by Chen et al. (2017), who used AVNIR 2 optical data in a mixed forest mountain area ( $R^{2}$ equal to 0.93), with higher values possibly thanks to the higher spatial resolution of AVNIR 2 with respect to Sentinel 2.

Sentinel 2 data are free of cost and have a very high revisiting time: the present research shows that this sensor can be an optimal choice for LAl estimation in a Mediterranean forest type. Band 4 (red band) and the ARVI vegetation index were the best predictors. Band 4 is linked to chlorophyll absorption, and thus to foliage density, and a recent study showed that this band can outperform other vegetation indices for LAl estimation (Hallik et al. 2019). ARVI, based on a combination of blue and red channels, has a dynamic range similar to that of NDVI, but it resists atmospheric effects via a self-correction process, making it a useful index in most remote-sensing applications (Kaufman \& Tanre 1992).

The accuracy of LAl estimates obtained with SAR data were lower than those obtained with multispectral data; the $\mathrm{R}^{2}$ was equal to 0.61 when all available SAR predictors (10) were used as input in the PLSR model, and to 0.71 when the ALOS HV channel - selected by stepwise regression - was used as input in the MLR model. The sensitivity to LAl of an HV cross-polarized signal is already known (Inoue et al. 2014); the present research shows that the use of SAR can be a valid alternative to multispectral data in the case of cloud coverage.

The longer wavelength of ALOS2, compared to S1, explains the complete exclusion of the latter dataset from the selection operated by stepwise regression. In fact, ALOS2 L-band data better penetrate the canopy and report information on vegetation density, with respect to C-band data (Canisius \& Fernandes 2012). Chen et

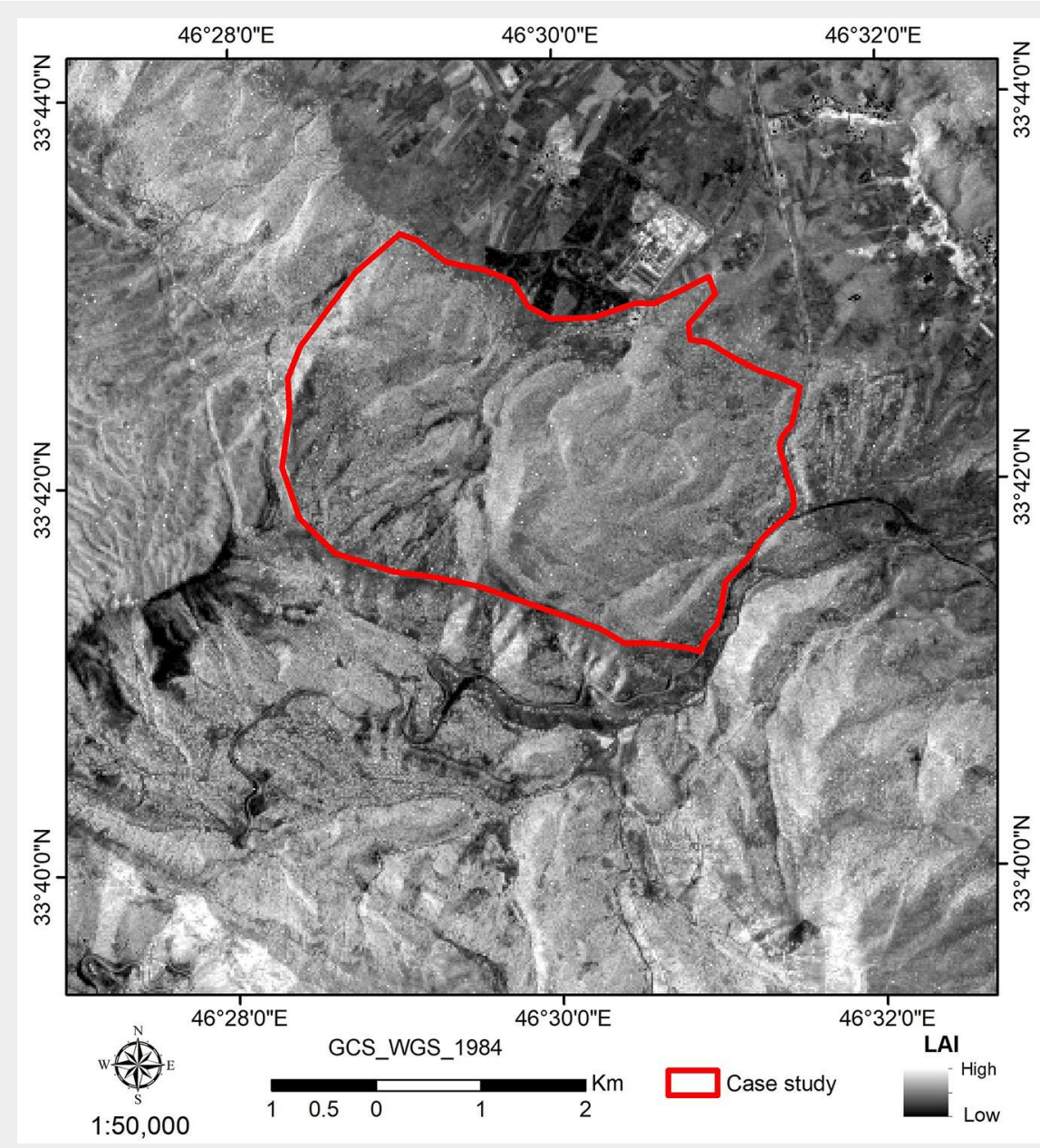

Fig. 4 - Map of the Leaf Area Index in the study area, based on Sentinel 2 and ALOS 2 data, using MLR model.

al. (2017) obtained results similar to those presented here using ALOS PALSAR to estimate forest LAI $\left(R^{2}=0.69\right)$, though no cross validation was performed in that study. Manninen et al. (2005) using ENVISAT ASAR data obtained results in the same range of accuracy $\left(\mathrm{R}^{2}=0.69\right)$ in boreal forests. Higher accuracy in the LAl estimate $\left(R^{2}=0.79\right)$ was obtained by Kovacs et al. (2013) using full-pol ALOS PALSAR data, characterized by four polarization channels and thus a higher information content.

The most accurate model was obtained integrating SAR ALOS 2 and multispectral S2 data: using MLR algorithm an accuracy $\left(R^{2}\right)$ equal to 0.84 was obtained. This result confirms the advantage, for the extraction of biophysical parameters in forests, of joining different datasets coming from complementary portions of the electromagnetic spectrum as previously observed by other authors (Vaglio Laurin et al. 2013). It is also worth noting that L-band data are scarcely influenced by the phenological stages of trees, as at this wavelength the signal is mainly influenced by the forest volume and the water content, thus allowing an easier comparison of LAl estimates carried out on different dates.

To conclude, the use of advanced algo- rithms such as RF or PLSR did not increase the accuracy of the LAl estimates with respect to MLR, possibly due to the clear linearity of the relationships. However, the use of MLR required a preliminary selection of predictors by stepwise regression, to prevent multicollinearity. To simplify the analysis, the PLSR algorithm is suggested as it can manage a large number of predictors; in this research, PLRS generated LAI estimates characterized by high accuracy $\left(R^{2}=0.80\right)$, in a range of values similar to those produced using MLR.

\section{Author's contribution}

Conception or design of the work: SV; methodology development: SV, OF, GVL; data collection: SV, OF, HF; data analysis and interpretation: SV, GVL, NP; drafting the article: SV, OF, SR; critical revision of the article: GVL.

\section{Acknowledgments}

This research was funded with the contribution of the Italian Ministry of Agricultural, Food, and Forestry Policies (MiPAAF) subproject "Precision Forestry" (AgriDigit program - DM 36503.7305.2018 of December 2, 2018). 


\section{References}

Baret F, Guyot G (1991). Potentials and limits of vegetation indices for $L A I$ and APAR assessment. Remote Sensing of Environment 35 (2-3): 161-173. - doi: 10.1016/0034-4257(91)90009-U

Blackburn GA (1998). Spectral indices for estimating photosynthetic pigment concentrations: a test using senescent tree leaves. International Journal of Remote Sensing 19 (4): 657675. - doi: 10.1080/014311698215919

Breiman L (2001). Random forests. Machine Learning 45: 5-32. - doi: 10.1023/A:10109334043 24

Brown LA, Ogutu BO, Dash J (2020). Tracking forest biophysical properties with automated digital repeat photography: a fisheye perspective using digital hemispherical photography from below the canopy. Agricultural and Forest Meteorology 287 (329): 107944. - doi: 10.1016/j. agrformet.2020.107944

Canisius F, Fernandes R (2012). ALOS PALSAR Lband polarimetric SAR data and in situ measurements for leaf area index assessment. Remote Sensing Letters 3 (3): 221-229. - doi: 10.108 o/01431161.2011.559288

Chen JM, Black TA (1992). Defining leaf area index for non-flat leaves. Plant, Cell and Environment 15 (4): 421-429. - doi: 10.1111/j.1365-3040.19 92.tboog92.x

Chen W, Yin H, Moriya K, Sakai T, Cao C (2017). Retrieval and comparison of forest leaf area index based on remote sensing data from AVNIR2, Landsat-5 TM, MODIS, and PALSAR sensors. ISPRS International Journal of Geo-Information 6 (6): 179. - doi: 10.3390/ijgi6060179

Clevers JG, Verhoef W (1993). LAl estimation by means of the WDVI: a sensitivity analysis with a combined PROSPECT-SAIL model. Remote Sensing Reviews 7 (1): 43-64. - doi: 10.1080/0275 7259309532165

Crippen RE (1990). Calculating the vegetation index faster. Remote sensing of Environment 34 (1): 71-73. - doi: 10.1016/0034-4257(90)90085-Z

Dash J, Curran PJ (2007). Evaluation of the MERIS terrestrial chlorophyll index (MTCI). Advances in Space Research 39 (1): 100-104. - doi: 10.1016/j.asr.2006.02.034

Daughtry CST, Walthall CL, Kim MS, De Colstoun EB, MCMurtrey JE (2000). Estimating corn leaf chlorophyll concentration from leaf and canopy reflectance. Remote Sensing of Environment 74 (2): 229-239. - doi: 10.1016/S0034-4257 (00)00113-9

Deering DW (1975). Measuring "forage production" of grazing units from Landsat MSS data. In: Proceedings of the " $10^{\text {th }}$ International Symposium of Remote Sensing of the Environment". ERIM, Ann Arbor, MI, USA, pp. 11691198.

Delegido J, Verrelst J, Meza CM, Rivera JP, Alonso L, Moreno J (2013). A red-edge spectral index for remote sensing estimation of green LAI over agroecosystems. European Journal of Agronomy 46: 42-52. - doi: 10.1016/j.eja.2012.12. 001

Díaz GM, Negri PA, Lencinas JD (2021). Toward making canopy hemispherical photography independent of illumination conditions: a deeplearning-based approach. Agricultural and Forest Meteorology 296: 108234. - doi: 10.1016/j.agr formet.2020.108234
Freedman DA (2009). Statistical models: theory and practice. Cambridge University Press, Cambridge, UK, pp. 459. [online] URL: http://books. google.com/books?id=fW_9BV5Wpf8C

Fournier RA, Landry R, August NM, Fedosejevs G, Gauthier RP (1996). Modelling light obstruction in three conifer forests using hemispherical photography and fine tree architecture. Agricultural and Forest Meteorology 82 (1-4): 47-72. - doi: 10.1016/0168-1923(96)02345-3

Gao S, Niu Z, Wu C (2010). Multi-polarization Envisat-ASAR images as a function of leaf area index (LAI) of white poplar and desert date plantations. International Journal of Remote Sensing 31 (4): 1095-1102. - doi: 10.1080/01431160903 283827

Geladi P, Kowalski BR (1986). Partial leastsquares regression: a tutorial. Analytica Chimica Acta 185: 1-17. - doi: 10.1016/0003-2670(86)8 0028-9

Gitelson AA, Kaufman YJ, Merzlyak MN (1996). Use of a green channel in remote sensing of global vegetation from EOS-MODIS. Remote Sensing of Environment 58 (3): 289-298. - doi: 10.1016/S0034-4257(96)00072-7

Guyot G, Baret F (1988). Utilisation de la haute resolution spectrale pour suivre l'etat des couverts vegetaux [Utilization of high spectral resolution to follow the state of vegetative covers]. In: Proceedings of the " 4 th Colloquium of Spectral Signatures of Objects in Remote Sensing”, Aussois-Modane (France) 18-22 Jan 1988. European Space Agency, Paris, France, vol. 287, pp. 279.

Hallik L, Kuusk A, Lang M, Kuusk J (2019). Reflectance properties of hemiboreal mixed forest canopies with focus on red edge and near infrared spectral regions. Remote Sensing 11 (14): 1717. - doi: 10.3390/rs11141717

Hardisky MA, Daiber FC, Roman CT, Klemas V (1984). Remote sensing of biomass and annual net aerial primary productivity of a salt marsh. Remote Sensing of Environment 16 (2): 91-106. doi: 10.1016/0034-4257(84)90055-5

Huete AR (1988). A soil-adjusted vegetation index (SAVI). Remote Sensing of Environment 25: 295-309. - doi: 10.1016/0034-4257(88)90106-X

Inoue Y, Sakaiya E, Wang C (2014). Capability of C-band backscattering coefficients from highresolution satellite SAR sensors to assess biophysical variables in paddy rice. Remote Sensing of Environment 140: 257-266. - doi: 10.1016/j. rse.2013.09.001

Jiao X, MCNairn H, Shang J, Pattey E, Liu J, Champagne $C$ (2011). The sensitivity of RADARSAT-2 polarimetric SAR data to corn and soybean leaf area index. Canadian Journal of Remote Sensing 37 (1): 69-81. - doi: 10.5589/m11-023

Kaufman YJ, Tanre D (1992). Atmospherically resistant vegetation index (ARVI) for EOS-MODIS. IEEE transactions on Geoscience and Remote Sensing 30 (2): 261-270. - doi: 10.1109/36.134076 Korhonen L, Packalen P, Rautiainen M (2017). Comparison of Sentinel-2 and Landsat 8 in the estimation of boreal forest canopy cover and leaf area index. Remote Sensing of Environment 195: 259-274. - doi: 10.1016/j.rse.2017.03. 021

Kovacs JM, Lu XX, Flores-Verdugo F, Zhang C, De Santiago FF, Jiao X (2013). Applications of ALOS PALSAR for monitoring biophysical parameters of a degraded black mangrove (Avicennia germinans) forest. ISPRS Journal of Photogrammetry and Remote Sensing 82: 102-111. - doi: 10.101 6/j.isprsjprs.2013.05.004

Leuschner C, Voß S, Foetzki A, Clases Y (2006). Variation in leaf area index and stand leaf mass of European beech across gradients of soil acidity and precipitation. Plant Ecology 186 (2): 247258. - doi: 10.1007/s11258-006-9127-2

Lu B, He Y (2019). Leaf area index estimation in a heterogeneous grassland using optical, SAR, and DEM Data. Canadian Journal of Remote Sensing 45 (5): 618-633. - doi: 10.1080/07038 992.2019.1641401

Mandal D, Hosseini M, McNairn H, Kumar V, Bhattacharya A, Rao YS, Mitchell $S$, Dingle Robertson L, Davidson A, Dabrowska-Zielinska $K$ (2019). An investigation of inversion methodologies to retrieve the leaf area index of corn from C-band SAR data. International Journal of Applied Earth Observation and Geoinformation 82: 101893. - doi: 10.1016/j.jag.2019.06.003

Manninen T, Stenberg P, Rautiainen M, Voipio P, Smolander H (2005). Leaf area index estimation of boreal forest using ENVISAT ASAR. IEEE Transactions on Geoscience and Remote Sens ing 43 (11): 2627-2635. - doi: 10.1109/TGRS.2005. 857325

Miller JB (1967). A formula for average foliage density. Australian Journal of Botany 15 (1): 141144. - doi: 10.1071/BT9670141

Norman JM, Campbell G (2000). Canopy structure. In: "Plant Physiological Ecology: Field Methods and Instrumentation" (Pearcy RW, Ehleringer JR, Mooney HA, Rundel PW eds). Springer, Dordrecht, Netherlands, pp. 301-325. doi: 10.1007/978-94-009-2221-1_14

Pereira LO, Furtado Novo LF EM, Sant'Anna SJ, Liesenberg V, Silva TS (2018). Multifrequency and full-polarimetric SAR assessment for estimating above ground biomass and leaf area index in the Amazon Várzea wetlands. Remote Sensing 10 (9): 1355. - doi: 10.3390/rs10091355

Qi J, Chehbouni A, Huete AR, Kerr YH, Sorooshian S (1994). A modified soil adjusted vegetation index. Remote Sensing of Environment 48 (2): 119-126. - doi: 10.1016/0034-4257(94)901 34-1

Richardson AJ, Wiegand CL (1977). Distinguishing vegetation from soil background information. Photogrammetric Engineering and Remote Sensing 43 (12): 1541-1552. [online] URL: http://www.asprs.org/wp-content/uploads/pers /1977journal/dec/1977_dec_1541-1552.pdf

Ross J (1981). The radiation regime and architecture of plant stands. Springer, Dordrecht, Netherlands, pp. 391. - doi: 10.1007/978-94-009-86473

Rousel JW, Haas RH, Schell JA, Deering DW (1974). Monitoring vegetation systems in the great plains with ERTS. In: Proceedings of the "Third Earth Resources Technology Satellite-1 Symposium: Section A-B. Technical presentations" (Freden SC, Mercanti EP, Becker MA eds). Washington (DC, USA) 10-14 Dec 1973. NASA Special Publications, SP-351, Paper A20, pp. 309-317. [online] URL: http://books.google. com/books?id=bn_xAAAAMAAJ

Sagheb-Talebi K, Pourhashemi M, Sajedi T (2014). Forests of Iran: a treasure from the past, a hope for the future. Springer, Dordrecht, Neth- 
erland, pp. 160.

Solberg S, Weydahl DJ (2007). SAR forest canopy penetration depth as an indicator for forest health monitoring based on leaf area index (LAI). In: Proceedings of the " $5^{\text {th }}$ International Symposium on Retrieval of Bio-and Geophysical Parameters from SAR Data for Land Applications". European Space Agency, Paris, France, pp. 25-28. [online] URL: http://www.researchga te.net/publication/228856212

Stankevich SA, Kozlova AA, Piestova IO, Lubskyi MS (2017). Leaf area index estimation of forest using sentinel-1 C-band SAR data. In: Proceedings of the "2017 IEEE Microwaves, Radar and Remote Sensing Symposium (MRRS)". Kiev (Ukraine) 29-31 Aug 2017. IEEE, pp. 253-256. doi: 10.1109/MRRS.2017.8075075

Stenberg P, Rautiainen M, Manninen T, Voipio P, Smolander H (2004). Reduced simple ratio better than NDVI for estimating LAI in Finnish pine and spruce stands. Silva Fennica (38) 1: 3-14. doi: 10.14214/sf.431

Torbick N, Ledoux L, Salas W, Zhao M (2016). Regional mapping of plantation extent using multisensor imagery. Remote Sensing 8 (3): 236. doi: $10.3390 /$ rs 8030236

Tucker CJ (1979). Red and photographic infrared linear combinations for monitoring vegetation. Remote Sensing of Environment 8 (2): 127-150. doi: 10.1016/0034-4257(79)90013-0

Vaglio Laurin G, Liesenberg V, Chen Q, Guerriero L, Del Frate F, Bartolini A, Coomes D, Wilebore B, Lidsell J, Valentini R (2013). Optical and SAR sensor synergies for forest and land cover mapping in a tropical site in West Africa. International Journal of Applied Earth Observation and Geoinformation 21: 7-16. - doi: 10.1016/j.jag.2012. 08.002

Van Dijk AIJM, Bruijnzeel LA (2001). Modelling rainfall interception by vegetation of variable density using an adapted analytical model. Part 1. Model description. Journal of Hydrology 247 (3-4): 230-238. - doi: 10.1016/S0022-1694(01)003 92-4

Verrelst J, Camps-Valls G, Muñoz-Marí J, Rivera JP, Veroustraete F, Clevers JG, Moreno J (2015). Optical remote sensing and the retrieval of terrestrial vegetation bio-geophysical properties A review. ISPRS Journal of Photogrammetry and Remote Sensing 108: 273-290. - doi: 10.1016/ j.isprsjprs.2015.05.005

Vittucci C, Laurin GV, Tramontana G, Ferrazzoli P, Guerriero L, Papale D (2019). Vegetation optical depth at L-band and above ground biomass in the tropical range: Evaluating their relationships at continental and regional scales. International Journal of Applied Earth Observation and Geoinformation 77: 151-161. - doi: 10.1016/j. jag.2019.01.006

Vose JM, Allen HL (1988). Leaf area, stemwood growth, and nutrition relationships in loblolly pine. Forest Science 34 (3): 547-563. [online] URL: http://academic.oup.com/forestscience/ article-abstract/34/3/547/4642485

Zhang Z, He G, Wang X, Jiang H (2011). Leaf area index estimation of bamboo forest in Fujian province based on IRS P6 LISS 3 imagery. International Journal of Remote Sensing 32 (19): 5365-5379. - doi: 10.1080/01431161.2010.498454 Zou J, Zuo Y, Zhong P, Hou W, Leng P, Chen B (2020). Performance of four optical methods in estimating leaf area index at elementary sampling unit of Larix principis-rupprechtii forests. Forests 11 (1): 30. - doi: 10.3390/f11010030

\section{Supplementary Material}

Tab. S1 - List of the 22 vegetation indices used in this study.

Link:Vafaei_3633@supplo01.pdf 